\title{
Psychiatric disorders in myasthenia gravis
}

\author{
Mariana Inés Ybarra', Arthur Kummer², \\ Elizabeth Regina Comini Frota ${ }^{3}$, José Teotônio de Oliveira ${ }^{3}$, \\ Rodrigo Santiago Gomez ${ }^{3}$, Antonio Lucio Teixeira ${ }^{1,3}$
}

\begin{abstract}
Objective: To investigate the prevalence of psychiatric disorders in patients with myasthenia gravis (MG). Method: Forty-one patients with MG answered to a structured psychiatric interview (MINI-Plus). Results: Eleven (26.1\%) patients were diagnosed with a depressive disorder and 19 (46.3\%) were diagnosed with an anxiety disorder. Patients with dysthymia were older $(p=0.029)$ and had longer disease duration $(p=0.006)$. Patients with social phobia also had longer disease duration $(p=0.039)$. Conclusion: Psychiatric disorders in MG are common, especially depressive and anxiety disorders.
\end{abstract}

Key words: myasthenia gravis, neuropsychiatry, mental health, depression.

\section{Transtornos psiquiátricos na miastenia gravis}

\section{RESUMO}

Objetivo: Investigar a prevalência de transtornos psiquiátricos em pacientes com miastenia gravis (MG). Método: Quarenta e um pacientes com MG responderam a uma entrevista psiquiátrica estruturada (MINI-Plus). Resultados: Onze (26,1\%) pacientes foram diagnosticados com transtorno depressivo e 19 (46,3\%) foram diagnosticados com um transtorno de ansiedade. Pacientes com distimia eram mais velhos $(p=0,029)$ e tinham maior tempo de doença $(p=0,006)$. Os pacientes com fobia social também tiveram maior tempo de doença $(p=0,039)$. Conclusão: Transtornos psiquiátricos na MG são bastante comuns, principalmente transtornos depressivos e de ansiedade.

Palavras-chave: miastenia gravis, neuropsiquiaria, saúde mental, depressão.

Myasthenia gravis (MG) is a prototypical autoimmune disease of the skeletal neuromuscular junction. The clinical symptoms of MG are caused by autoantibodies which in most cases attack the postsynaptic nicotinic acetylcholine receptor (AChR) of the muscle endplate ${ }^{1,2}$. In other cases, non-AChR components of the postsynaptic endplate, such as the muscle-specific receptor tyrosine kinase (MuSK), might be attacked by autoantibodies $^{1}$. Accordingly, the characteristic symptom of MG is a fluctuating muscle weakness that increases with effort.

Besides motor impairment, MG has been somewhat associated with other neurological symptoms since its first de- scriptions. For instance, old studies reported increased incidence of epilepsy and electrophysiological changes in patients with $\mathrm{MG}^{3,4}$. Sleep disorders and memory impairment have also been described in MG, as the cholinergic system plays a major role in these functions ${ }^{5,6}$. However, the inappropriate methods of these previous studies precluded the establishment of any causal relationship between these findings and disruption of cholinergic neurotransmission ${ }^{2}$. In addition, more recent studies have argued against central nervous system (CNS) compromise in $\mathrm{MG}^{7}$. On the other hand, MG is an autoimmune disease and as such can potentially interfere on the brain 
function determining behavioral changes, such as depressive disorders and suicidal behavior ${ }^{8}$. Moreover, regarding MG as a chronic, debilitating, life-threatening disease with unpredictable progression, a psychological reaction may be expected in patients diagnosed with the disease ${ }^{9}$. Thus, subject with MG may be at increased risk of psychiatric disorders. Unfortunately studies that systematically investigate psychiatric disorders in MG are scarce. This situation is possibly due to the lower prevalence of MG and a comparatively lower interest to study mental features of the disease $\mathrm{e}^{10}$.

In the current study we aimed to investigate the frequency of psychiatric disorders in a Brazilian sample of subjects with MG.

\section{METHOD}

This cross-sectional study included 41 consecutive patients with MG attended at the Neuromuscular Disorders Clinic of University Hospital of the Federal University of Minas Gerais (UFMG), Brazil. A nonprobability purposive sampling method was used because of the rarity of the disease. After their appointment with their neurologist, patients were invited to participate in this study. No patient refused to participate. This study was approved by the local ethics committee, and all subjects gave their written informed consent.

Demographic and clinical data were obtained. Diagnosis of MG was confirmed by detection of acetylcholine receptor antibodies in serum and/or electromyographic evidence consistent with the disease. Patients underwent a psychiatric examination comprised of an internationally validated structured psychiatric interview (MINI-Plus) ${ }^{11}$.

Comparisons of categorical data were performed using Fisher's exact test. The Mann-Whitney U test was employed for continuous variables. All $p$-values were two-tailed and a significance level of 0.05 was chosen. Statistical analysis was performed using the SPSS v15.0 software (SPSS Inc., Chicago, IL, USA).

\section{RESULTS}

Forty-one patients participated in this study. The sample was composed mainly by females in the fourth decade of life (Table 1). Most patients had the generalized form of the disease. The mean (SD) disease duration was 10.3 (8.0) years and the mean (SD) age of disease onset was 27.1 (13.6) years. A significant proportion of patients (43.9\%) was retired or receiving social security disability compensation due to $\mathrm{MG}$, and just $29.3 \%$ of them were working. Thirty patients $(73.2 \%)$ were in use of corticoids, 35 (85.4\%) were in use of piridostigmine and $10(24.4 \%)$ were in use of azathioprine.

More than a quarter of the patients $(26.1 \%)$ were suffering from a depressive disorder (Table 2). Three (7.3\%)
Table 1. Demographic and clinic characteristics of 41 patients with myasthenia gravis (MG) followed at the Neuromuscular Disorders Clinic of the University Hospital of the Federal University of Minas Gerais (UFMG), Brazil.

\begin{tabular}{lc}
\hline Psychiatric disorders & Patients (N=41) \\
\hline Male / Female & $9(21.9 \%) / 32(78.1 \%)$ \\
Age, mean (SD), years & $37.4(13.4)$ \\
Age of disease onset, mean (SD), years & $27.1(13.6)$ \\
Disease duration, mean (SD), years & $10.3(8.0)$ \\
Marital status & \\
Married or with a companion & $21(51.2 \%)$ \\
Single & $14(34.1 \%)$ \\
Divorced & $4(9.8 \%)$ \\
Widowed & $2(4.9 \%)$ \\
Employment status & $12(29.3 \%)$ \\
Employed & $9(21.9 \%)$ \\
Unemployed & $18(43.9 \%)$ \\
Retired due to MG & $2(4.9 \%)$ \\
Retired by age & $3(7.3 \%) / 38(92.7 \%)$ \\
Ocular form / Generalized form & \\
Medication & $30(73.2 \%)$ \\
Corticoids & $35(85.4 \%)$ \\
Piridostigmine & $10(24.4 \%)$ \\
Azathioprine &
\end{tabular}

of them had suicidal ideation. Patients with dysthymia were older $(p=0.029)$ and had longer disease duration $(p=0.006)$. The frequency of anxiety disorders was also remarkably high (46.3\%). Female gender associated with specific phobia $(\mathrm{p}=0.010)$. Patients with social phobia had longer disease duration $(\mathrm{p}=0.039)$ and were in use of lower doses of corticoids ( $\mathrm{p}=0.013)$. No patient was diagnosed with psychosis. Psychiatric disorders did not associate with the type of pharmacotherapy.

\section{DISCUSSION}

Our study has shown a high prevalence of psychiatric disorders in MG, especially depressive and anxiety disorders, in comparison to what is expected in the general population. These results are in line with previous studies about psychiatric disorders in MG. For instance, Magni et al. examined 74 patients with MG and observed that $14 \%$ fit DSM-III criteria for an affective disorder and $22 \%$ had adjustment disorder with depressed mood and mixed emotional features ${ }^{12}$. However, the frequency of anxiety disorders in the study by Magni et al. was remarkably low. By contrast, Paradis et al. reported increased rates of panic disorder (7\%) in $\mathrm{MG}^{13}$. These authors speculate whether fluctuating respiratory symptoms of MG predispose vulnerable individuals to develop 
Table 2. Frequency of psychiatric disorders in patients with myasthenia gravis.

\begin{tabular}{lccc}
\hline & \multicolumn{3}{c}{ Patients (N=41) } \\
\cline { 2 - 4 } Psychiatric disorders & $\mathrm{N}$ & Proportion & $\begin{array}{c}\text { 95\% Confidence Interval } \\
\text { (Lower limit-Upper limit) }\end{array}$ \\
\hline Depressive disorders & 11 & $26.1 \%$ & $(13.3 \%-40.4 \%)$ \\
Major depression & 7 & $17.1 \%$ & $(5.6 \%-28.6 \%)$ \\
Dysthymia & 4 & $9.8 \%$ & $(0.7 \%-18.8 \%)$ \\
Bipolar disorder & 1 & $2.4 \%$ & $(0 \%-7.2 \%)$ \\
Anxiety disorders & 19 & $46.3 \%$ & $(31.1 \%-61.1 \%)$ \\
Generalized anxiety disorder & 10 & $24.4 \%$ & $(11.3 \%-37.5 \%)$ \\
Panic disorder & 7 & $17.1 \%$ & $(5.6 \%-28.6 \%)$ \\
Social anxiety disorder & 14 & $34.1 \%$ & $(19.6 \%-48.7 \%)$ \\
Specific phobia disorder & 15 & $36.6 \%$ & $(21.8 \%-51.3 \%)$ \\
Obsessive-compulsive disorder & 4 & $9.8 \%$ & $(0.7 \%-18.8 \%)$ \\
Psychotic disorder & 0 & $0 \%$ & $(0 \%-0 \%)$ \\
Suicidal ideation & 3 & $7.3 \%$ & $(0 \%-15.3 \%)$ \\
\hline
\end{tabular}

panic disorder and/or agoraphobia. Although anxiety and depressive disorders are probably more frequent in MG patients with respiratory failure, these psychiatric disorders are also prevalent in patients without any respiratory complaint ${ }^{14}$. Higher levels of anxiety and tension were also observed by other authors ${ }^{15,16}$. Unfortunately, we were not able to evaluate whether anxiety was more frequent in patients with respiratory problems. Bulbar impairment could also explain social anxiety symptoms due to dysphonia, dysarthria and dysphagia.

Sitek et al. showed that MG patients scored higher in the Beck Depression Inventory than healthy controls ${ }^{7}$. Conversely Paul et al. observed that somatic symptoms of depression might be misleading in patients with MG, suggesting that the frequency of depression in MG may be similar to the one found in healthy population ${ }^{17}$. It seems that psychiatric disorders in MG are truly more prevalent than in general population, although their frequency probably does not exceed the prevalence of psychiatric disorders in other chronic illnesses ${ }^{2,18}$. Hence, psychopathology in MG is possibly due to a psychological reaction to a chronic and unpredictable disease rather than a result of CNS involvement.

Data concerning predictors of psychopathology in MG are still scarce. We observed that longer disease duration was associated with dysthymia and social phobia. Other studies suggested that psychopathology was more prevalent in females and correlated with disease severity $^{12,19}$. Paradis et al. found no association between the severity of the disease and anxiety disorders ${ }^{13}$. Also, psychopathology has not been associated with steroid therapy, thymectomy, or age of MG onset ${ }^{12}$. Nevertheless, corticosteroids have been associated with depres- sion in several clinical populations ${ }^{20}$. Indeed, it is known that corticosteroids can alter the levels of monoamines and induce behavioral change, but the use of corticoids was not associated only with depression in this study ${ }^{21}$.

Our study has some limitations. First, patients were recruited in a tertiary center where more complex and severe patients are usually attended. Thus, our results may not be representative of MG patients in general. Second, a type II error of our study cannot be ruled out due to the relatively small sample size enrolled in the study. However, it must be taken into account that MG is an uncommon disease and this study included one of the largest cohort of MG patients of the neuropsychiatric literature. The lack of a control group composed of healthy individuals or patients with other chronic disease is another limitation. Last but not least, considering that current literature has mixed results regarding the association between disease severity and psychopathology $y^{12,13,19}$, it would be of utmost importance a detailed quantitative assessment of the severity of the disease and a more comprehensive classification of the patients based on the Myasthenia Gravis Foundation of America Clinical Classification ${ }^{22}$. We hope that future studies will overcome these limitations.

In conclusion, psychiatric disorders in MG are frequent, particularly depressive and anxiety disorders. It is already known that these disorders impact in quality of life of subjects with $\mathrm{MG}^{23}$. Clinicians should investigate these disorders in order to reduce disease burden.

\section{REFERENCES}

1. Meriggioli MN, Sanders DB. Autoimmune myasthenia gravis: emerging clinical and biological heterogeneity. Lancet Neurol 2009:8:475-490.

2. Keesey JC. Does myasthenia gravis affect the brain? J Neurol Sci 1999;170: 77-89. 
3. Hoefer PF, Aranow H Jr., Rowland LP. Myasthenia gravis and epilepsy. AMA Arch Neurol Psychiatry 1958;80:10-17.

4. Hokkanen E, Toivakka E. Electroencephalographic findings in myasthenia gravis: 180 EEG recordings of 109 patients. Acta Neurol Scand 1969;45:556-567.

5. Tucker DM, Roeltgen DP, Wann PD, Wertheimer RI. Memory dysfunction in myasthenia gravis: evidence for central cholinergic effects. Neurology 1988:38:1173-1177.

6. Papazian O. Rapid eye movement sleep alterations in myasthenia gravis. Neurology 1976;26:311-316.

7. Sitek EJ, Bilinska MM, Wieczorek D, Nyka WM. Neuropsychological assessment in myasthenia gravis. Neurol Sci 2009;30:9-14.

8. Dantzer R. Cytokine, sickness behavior, and depression. Neurol Clin 2006; 24:441-460.

9. Kulaksizoglu I. Mood and anxiety disorders in patients with myasthenia gravis: aetiology, diagnosis and treatment. CNS Drugs 2007;21:473-481.

10. Paul RH, Mullins LL, Gilchrist JM. The impact of myasthenia gravis on mood, cognitive function, and quality of life. In: Kaminski HJ, (Ed.). Myasthenia gravis and related disorders. $2^{\text {nd }}$ Ed. New York: Humana Press, 2009.

11. Sheehan DV, Lecrubier Y, Sheehan KH, et al. The Mini-International Neuropsychiatric Interview: the development and validation of a structured diagnostic psychiatric interview for DSM-IV and ICD-10. J Clin Psychiatry 1998;59:22-33.

12. Magni G, Micaglio GF, Lalli R, et al. Psychiatric disturbances associated with myasthenia gravis. Acta Psychiatr Scand 1988;77:443-445.

13. Paradis CM, Friedman S, Lazar RM, Kula RW. Anxiety disorders in a neuromuscular clinic. Am J Psychiatry 1993;150:1102-1104.
14. Eren I, Kulaksizoglu IB, Anuk D. Post traumatic stress disorder in myasthenia gravis patients [abstract]. ESTSS $6^{\text {th }}$ European Congress on Traumatic Stress 1999:147-148.

15. Bartel PR, Lotz BP. Neuropsychological test performance and affect in myasthenia gravis. Acta Neurol Scand 1995;91:266-270.

16. Lundeen J, Fisher J, Kothari MJ. Frequency of anxiety in myasthenia gravis. J Clin Neuromuscul Dis 2004;6:9-12.

17. Paul RH, Cohen RA, Goldstein JM, Gilchrist JM. Severity of mood, selfevaluative, and vegetative symptoms of depression in myasthenia gravis. J Neuropsychiatry Clin Neurosci 2000;12:499-501.

18. Stewart SB, Robertson KR, Johnson KM, Howard JF. The prevalence of depression in myasthenia gravis. J Clin Neuromuscul Dis 2007:8:111-115.

19. Doering S, Henze T, Schussler G. Coping with myasthenia gravis and implications for psychotherapy. Arch Neurol 1993;50:617-620.

20. Patten SB. Exogenous corticosteroids and major depression in the general population. J Psychosom Res 2000;49:447-449.

21. Pretorius E. Corticosteroids, depression and the role of serotonin. Rev Neurosci 2004:15:109-116.

22. Jaretzki A $3^{\text {rd }}$, Barohn RJ, Ernstoff RM, et al. Myasthenia gravis: recommendations for clinical research standards. Task Force of the Medical Scientific Advisory Board of the Myasthenia Gravis Foundation of America. Neurology 2000;55:16-23.

23. Paul RH, Nash JM, Cohen RA, Gilchrist JM, Goldstein JM. Quality of life and well-being of patients with myasthenia gravis. Muscle Nerve 2001;24: 512-516. 